\title{
Research on schedule control method of EPC general contract project based on Technology Management
}

\author{
Ping Zhou ${ }^{1 *}$, Cheng $\operatorname{Jin}^{1}$, Shengming Xiao ${ }^{1}$ and Tie Jiang ${ }^{1}$ \\ ${ }^{1}$ Power China Huadong Engineering Corporation Limited, Hangzhou, Zhejiang, 311122, China
}

\begin{abstract}
In order to improve the effect of EPC project schedule control, increase the precision of project control, and achieve the best project management benefits, this paper proposes a schedule control method of EPC general contract project based on technical management. The audit process of project contracting is used to optimize the management content of EPC project, and the schedule control of EPC project is realized by managing EPC project information, controlling EPC project schedule and adjusting the progress of cost engineering project. In order to verify the control effect of this method on EPC project schedule, a comparative experiment is designed. This method can effectively improve the project control accuracy, ensure the project cost and quality, and complete the operation and management objectives of the construction project in a reasonable time.
\end{abstract}

\section{Introduction}

The general progress control of the project is to track, track and correct the project according to the plan made in advance during the implementation of the project ${ }^{[1]}$. The core content and main control objective of EPC project schedule control is schedule control, including design cycle, supplier cycle, construction cycle, etc. According to the project plan, analyze the actual workload and judge whether there is deviation. If the actual work of the previous stage needs to be carried out according to the plan, then the work of the next stage can also be carried out according to the plan; if there is a deviation, the reason should be found out to determine whether the deviation affects the work of the next stage ${ }^{[2]}$. Correct the adverse reactions in time. Schedule control is the guarantee for the realization of EPC project objectives and an important part of project management. General contracting is the combination of design and construction, and schedule control is a goal that needs to be controlled in the construction process. In the whole process of engineering design, procurement and construction, speed control sensitivity, speed control materials, speed control materials and other resources play an important role ${ }^{[3]}$. Project schedule control is an important link in the implementation of EPC project. On this basis, the comprehensive allocation of various resources can be realized, so as to grasp each construction point and achieve the progress target.

\section{Progress control method of EPC project}

\section{1 optimization of EPC project management content}

The progress control of project general contracting refers to the process of tracking, checking, adjusting and correcting the project progress according to the plan formulated first in the process of project implementation. The core of project schedule control is the project, which is the main control objective of EPC project management, including total construction period, design period, equipment and material supply cycle, construction period, key node milestone, etc[4]. According to the plan to determine whether there is deviation, and according to the actual amount of work done. If the actual work of the previous stage is carried out according to the plan, the next stage can also be carried out according to the plan; if there is any deviation, the reasons should be found out to determine whether the work in the next stage will be affected. If the impact is serious, remedial measures should be taken[5]. Project schedule control is an important content of objective management of EPC general contracting project, and is also important to achieve the quality, cost and objectives of the project.

Table 1 Contents of target management of EPC project

\begin{tabular}{ll}
\hline Control objectives & \multicolumn{1}{c}{ Main control tasks } \\
\hline progress control & $\begin{array}{l}\text { Make the construction sequence reasonable, the connection relationship } \\
\text { appropriate, balanced, rhythmic construction, realize the planned } \\
\text { construction period, and complete the contract period in advance }\end{array}$ \\
\hline
\end{tabular}

\footnotetext{
*Corresponding author: zhou_p2@ecidi.com
} 


\begin{tabular}{ll}
\hline Quality Control & Make part of the project meet the requirements of quality inspection and \\
evaluation standards, realize the technical organization measures and \\
quality level to ensure the construction quality in the construction \\
organization, and ensure the realization of the contract quality grade \\
To achieve the cost reduction measures of construction organization design, \\
reduce the direct cost of each sub project, achieve the profit target of the \\
project management department, and achieve the company's profit target \\
and contract cost \\
Realize the safety design and measures of construction organization design, \\
control the laborer, labor means and labor object, control the environment, \\
realize the safety goal, make people's behavior safety, material state safety, \\
cut off the environmental hazard source \\
safety control \\
Organize the construction scientifically to make the site appearance, \\
materials and tools stacking and management, fire protection, \\
environmental protection and staff life meet the requirements \\
Provide the basis and premise for the output of each target \\
Caving, quality, safety, environmental protection, winter construction, cost \\
construction plan \\
Technical organization measures \\
Construction schedule
\end{tabular}

At present, the design schedule control of EPC project needs to prepare reasonable schedule and retrieve design data to lay a good foundation for the follow-up schedule control. Without corresponding plans, the project can not be carried out smoothly ${ }^{[6]}$. Therefore, in order to promote the progress of design work and meet the requirements of project implementation, the design department needs to formulate a schedule before the implementation of the project to provide guidance documents for the smooth implementation of the design work. In the planning, the design period should be considered, the relationship among design, procurement and construction should be analyzed, the contents of design and construction should be clarified, and a feasible schedule should be formulated ${ }^{[7]}$. The schedule of large-scale projects generally includes master plan, partition plan and master plan. The design progress must be fully developed and adjusted according to the actual design progress. Please refer to the design flow chart as follows:

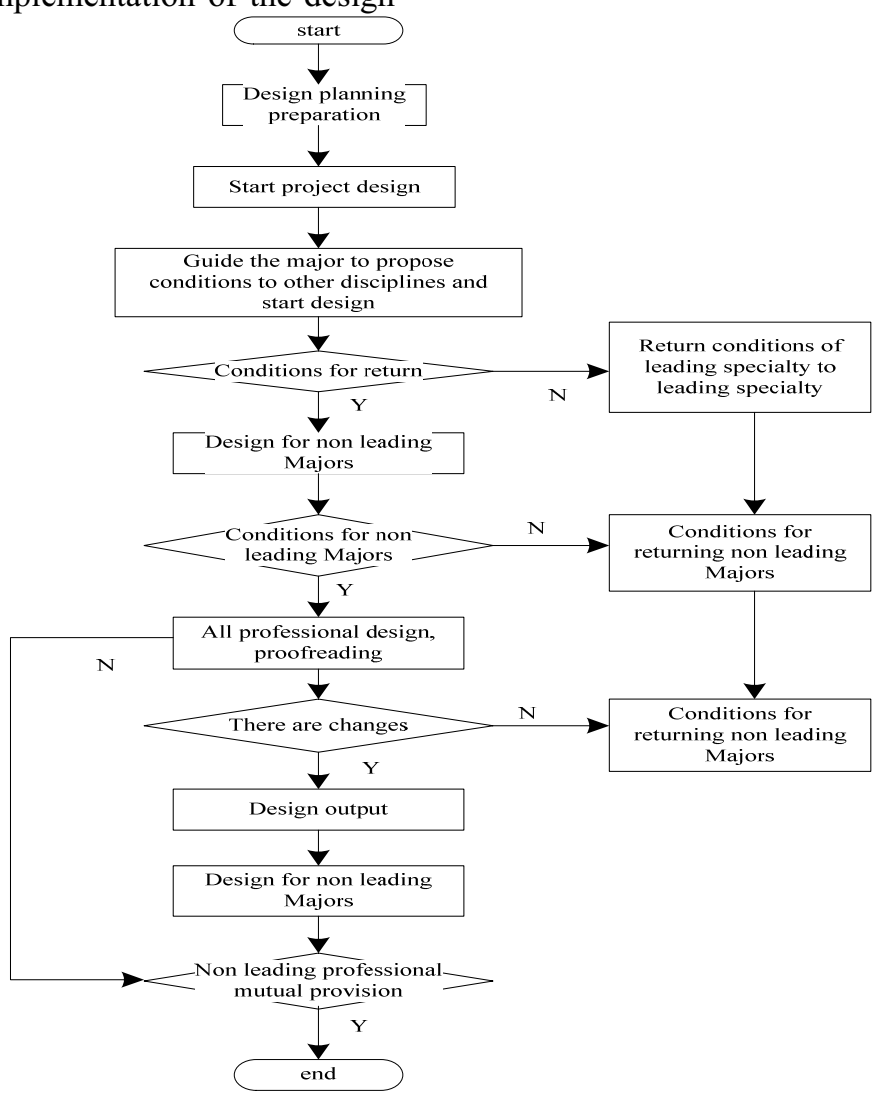

Fig.1 project contracting audit process 
As there are many engineering projects, there are many conditions proposed or approved by various disciplines. Only when the design data are accurate and complete can the requirements of engineering design be met, which is the basic guarantee for the smooth progress of engineering design. Therefore, for the design department, in the engineering design preparation stage, it is necessary to collect all kinds of data; for various specialties, in the engineering design implementation stage, in addition to accepting the design conditions proposed by the major categories, it is also necessary to timely and accurately put forward the conditions to the major categories, and urge the major categories to put forward the conditions as soon as possible to ensure the smooth completion of the project

\subsection{Information management of EPC project}

Construction projects are divided into contracted projects, highway projects, hydropower projects, etc. according to their specialties, there are 33 major categories in the Ministry of construction. According to the different operation modes, it can be divided into construction engineering, design engineering, consulting engineering and construction engineering. There is no clear boundary in the operation stages of general contracting project, especially in the design, procurement and construction stages. The general contracting project management should give full play to the main advantages of the general contract and coordinate the implementation of the project. Reasonable project management and effective use of cross operation can effectively save $35 \%$ of the investment and shorten more than $30 \%$ of the construction period. From the perspective of the general contractor, this chapter discusses the various stages of EPC project management.

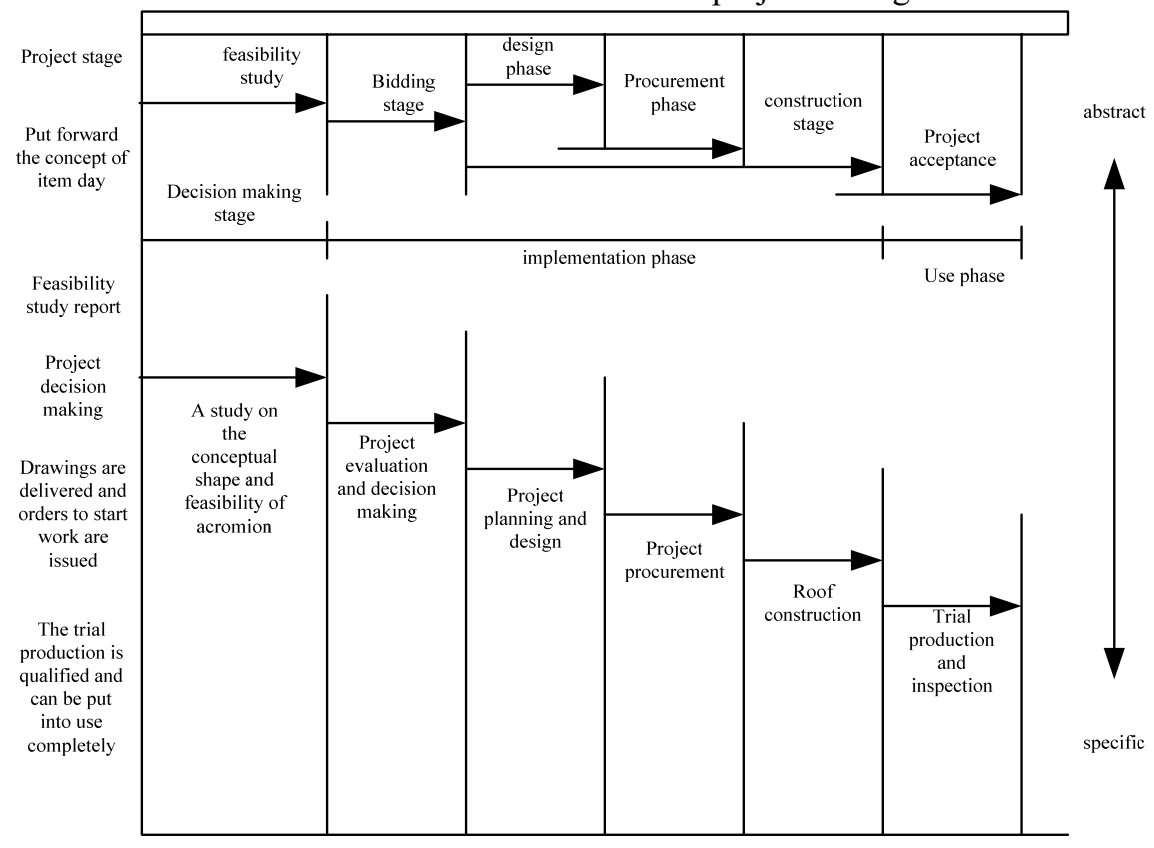

Fig. 2 EPC project management stage

Based on the above steps, the progress information of the general contracting project is collected and managed reasonably, and the control optimization is carried out according to the information management planning steps to ensure the effect of information progress control.

\subsection{Implementation of EPC project control}

EPC project involves many aspects, even the project manager is difficult to understand and arrange the needs of all aspects in time. As the descriptors of project products, designers can plan around the overall progress and cost of engineering products, and establish standardized design management documents including construction, procurement and other information. In order to ensure the construction progress, the design sequence of each sub project or unit project should be reasonably arranged according to the construction difficulty, risk and construction sequence, so as to facilitate the deep intersection of design and construction, and improve the possibility of the overall schedule being completed on time. The influence degree of the project progress is obtained by comparing the actual progress with the planned progress. Through the comparison of project progress, find out the causes of project progress deviation, formulate countermeasures, and control the project progress. The commonly used progress comparison methods are: cross chart method, scale curve method, list curve method, S-curve method and actual progress comparison method. The following formula represents the schedule deviation algorithm of EPC project:

$$
\Delta d=\iint t_{p}-t_{s}
$$

In the above algorithm, $d$ is the project progress 
deviation, $t_{p}$ is the actual completion time of the project, and $t_{s}$ is the planned completion time. Furthermore, the earned value method is used to analyze the progress deviation of EPC project, which can not only reflect the progress deviation in time, but also analyze the causes of the deviation combined with cost management.

$$
\Delta d_{c}=\prod\left(c_{\mathrm{p}}-c_{s}\right) /\left(\mathrm{t}_{\mathrm{p}}-\mathrm{t}_{\mathrm{s}}\right)
$$

In the formula, $\Delta d_{c}$ is the progress deviation of the project, $c_{\mathrm{p}}$ is the cost of the expected completion process, and $c_{s}$ is the budget cost of the planned project.

In the process of project implementation, due to the deviation of human resources, equipment and other factors with the plan, the project task can not be completed on time, resulting in the contradiction between budget cost and planned cost. Therefore, when evaluating a project, we must link time with cost. When there is deviation between the actual progress and the plan, the causes and effects of the deviation shall be analyzed in time, the plan shall be adjusted and positive measures shall be taken to make the project completed smoothly.

\section{Analysis of experimental results}

In order to verify the practical application effect of the schedule control method of EPC general contracting project based on technical management, a enterprise is selected as a pilot project for investigation. As one of the first batch of pilot projects in China, a engineering company undertook the overall design of a petrochemical clean fuel production technical transformation project and the design of atmospheric distillation unit, sulfur recovery unit and general substation. On this basis, it completed the 500000 ton catalytic cracking unit (MIP process), $30 \mathrm{t} / \mathrm{A}$ diesel oil hydrofining unit, $4000 \mathrm{Nm} 3 / \mathrm{h}$ hydrogen production unit and related supporting facilities EPC general contract, the total investment is about 320 million yuan. Based on the above situation, the expected value of project contracting schedule control and the actual value under the guidance of the method in this paper are compared and recorded as follows:

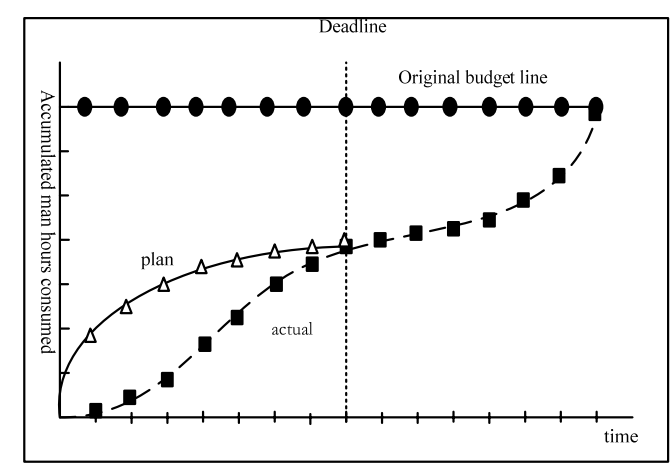

Fig. 3 schedule control effect of EPC project
Based on the analysis of the above inspection results, it can be seen that the progress control method proposed in this paper is relatively close to the expected curve in the actual application process, and the engineering consumption value is significantly reduced under the EPC general contracting project control method. Further, the control accuracy of the traditional cost control management method and the method in this paper is compared and recorded. The specific test results are as follows As shown in the figure below:

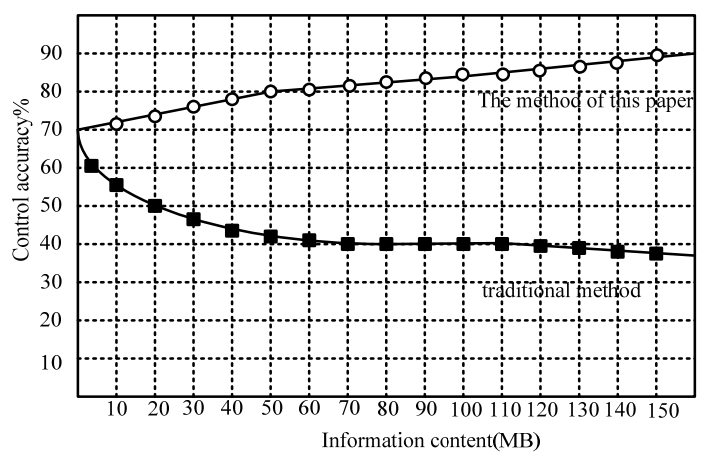

Fig. 4 comparison test results

Based on the above detection results, compared with the traditional control method, the proposed schedule control method of EPC project in this paper has higher control accuracy and better effectiveness in the actual application process, which fully meets the research requirements.

\section{Conclusion}

This paper mainly analyzes the progress control problems in EPC project, and carries out empirical research combined with the actual situation, in order to help in theory and practice. Summary and communication after project implementation is very important. This paper analyzes and expounds the key and difficult problems in the process of engineering construction, and introduces the good management methods and existing deficiencies in the process of project construction schedule control. The overall planning and layout is reasonable, the key lines and tasks are arranged reasonably, the difficulties of engineering construction are prominent, the engineering design standardization, procurement standardization, construction modularization, personnel input rationalization, organization setting reasonable, site coordination management reasonable, engineering construction procedures in line with the reality, with good project implementation experience, which can provide reference for subsequent engineering construction.

\section{Reference}

1. Sols A, Romero J, Ramiro E. Lessons Learned from Technical Reviews in Systems Engineering 
Management - Recommendations to Practitioners[J]. Journal of Integrated Design and Process Science, 2019, 22(2):1-17.

2. Ramasubbu N, Kemerer C F. Integrating Technical Debt Management and Software Quality Management Processes: A Normative Framework and Field Tests[J]. IEEE Transactions on Software Engineering, 2019, 45(3):285-300.

3. Rios N, Gomes D M N M, Spinola R O. A tertiary study on technical debt: Types, management strategies, research trends, and base information for practitioners[J]. Information and software technology, 2018, 102(1):117-145.

4. Boegel P, Pereverza K, Upham P, et al. Linking socio-technical transition studies and organisational change management: Steps towards an integrative, multi-scale heuristic[J]. Journal of Cleaner Production, 2019, 232(1):359-368.

5. Bruce J R, De Figueiredo J M, Silverman B S. Public contracting for private innovation: Government capabilities, decision rights, and performance outcomes[J]. Strategic Management Journal, 2019, 40(4):533-555.

6. Thimm H. Energy Management Enhanced ERP Use Cases, Technical Considerations, and a Sample Implementation Approach[J]. International Journal of Enterprise Information Systems, 2018, 14(4):1-15.

7. Sefeedpari P, Vellinga T, Rafiee S, et al. Technical, environmental and cost-benefit assessment of manure management chain: A case study of large scale dairy farming[J]. Journal of Cleaner Production, 2019, 233(1):857-868. 